\section{Multiple hepatic hemangiomas in a Nigerian man}

\author{
Abiodun Christopher Jemilohun, ${ }^{1}$ \\ Taofeek Abiodun Ajadi, ${ }^{2}$ \\ Modupeola Maria Bello \\ ${ }^{1}$ Department of Medicine and \\ ${ }^{2}$ Department of Radiology, Ladoke \\ Akintola University of Technology \\ Teaching Hospital, Ogbomoso, Oyo \\ State, Nigeria
}

\begin{abstract}
Hepatic hemangiomas are benign tumors of the liver which are often found incidentally. We present a 34-years-old man with a two-month history of upper abdominal pain and incidental finding of multiple hepatic masses. The patient sought medical attention at several healthcare facilities where he posed a diagnostic dilemma before he was referred to us. Computed tomographic scan revealed four hypodense hepatic nodules of varying sizes. The nodules demonstrated peripheral enhancement with progressive centripetal filling till they were totally filled during the delayed phase. Abdominal ultrasonography confirmed the four hepatic lesions. The largest lesion was in the left lobe measuring $73 \times 72 \mathrm{~mm}$ while the smallest was in the right lobe $(24 \times 20$ $\mathrm{mm})$. All the masses demonstrated increased vascularity on color Doppler imaging. The paucity of reported cases of hepatic hemangioma in Nigeria, the multiplicity of the tumor and the giant size of one of them make this case remarkable and reportable.
\end{abstract}

\section{Introduction}

Hepatic hemangiomas are the most common benign tumor of the liver which are often found incidentally during abdominal imaging studies, exploratory abdominal surgeries or autopsy. ${ }^{1,2}$ They account for about $73 \%$ of all benign tumors of the liver. ${ }^{3}$ They are composed of masses of blood vessels that are atypical or irregular in arrangement and size. ${ }^{1}$ Hepatic hemangiomas are often solitary, although they could be multiple with involvement of both lobes of the liver in $40 \%$ of cases. ${ }^{1,4}$

Hepatic hemangiomas are divided into two major groups: capillary and cavernous. Capillary hemangiomas are small, often peripheral, multiple and may be found in other organs while the cavernous type is usually large, solitary and limited to the liver. ${ }^{1,4}$ Hemangiomas of the liver have been defined as giant based on different sizes but most authors use a cut-off of 4 cm. ${ }^{3,5}$ They are mostly asymptomatic because of their small sizes but giant ones could become symptomatic due to rupture or pressure effect. ${ }^{1}$

The prevalence of hepatic hemangioma in Nigeria is not known. We found only one reported case, which was a small solitary tumor that occurred in association with focal nodular hyperplasia, in our literature review. ${ }^{6}$ To the best of our knowledge, this is the second reported case of hepatic hemangioma in Nigeria.

\section{Case Report}

A 34-years-old man was referred to our clinic because of a two-month history of upper abdominal pain and incidental finding of multiple hepatic masses by radioimaging.

The patient had been treated for dyspepsia for about a year before the onset of a new abdominal pain that involved the right hypochondrium and the epigastrium.

The pain was dull and intermittent with no known aggravating or relieving factors. The pain radiated to the back occasionally. There was no associated history of weight loss, anorexia, early satiety or difficulty in swallowing. No history of jaundice. He did not use non-steroidal anti-inflammatory drugs (NSAID). No history of abdominal swelling, altered bowel habit, hematemesis, melena or hematochezia. He did not consume alcohol or smoked cigarette. There was no significant finding on physical examination. The patient had been evaluated for the primary source of supposed hepatic metastatic tumors at several health facilities before he was referred to our facility. Fine needle aspiration cytology of the liver that was performed at one of the facilities a month before presenting to us yielded hemorrhagic smear on histology. He had several abdominal ultrasound scans at the various health facilities where he presented that all reported multiple hepatic masses of varying sizes, suggesting hepatic metastatic lesions.

Upper gastrointestinal endoscopy and colonoscopy performed at our instance were essentially normal. The complete blood count was normal. The electrolytes, urea, and creatinine were normal, except for a mild hypernatremia of $145 \mathrm{mmol} / \mathrm{L}$. The results of other relevant laboratory tests are
Correspondence: Abiodun Christopher Jemilohun, Department of Medicine, LAUTECH Teaching Hospital, P.M.B. 4007, Ogbomoso, Oyo State, Nigeria.

Tel.: +234.803867462

E-mail: chrislohun2010@hotmail.com

Key words: Hepatic hemangioma, Multiple hemangiomas, Benign hepatic tumors, Nigeria.

Contributions: ACJ: study conception and design, manuscript writing and critical review of manuscript content. TAA: performed abdominal ultrasonography, abdominal CT scan review and manuscript review. MMB: drafted the initial manuscript

Conflict of interest: the authors declare no potential conflict of interest

Received for publication: 8 February 2016. Accepted for publication: 14 December 2016.

This work is licensed under a Creative Commons Attribution NonCommercial 4.0 License (CC BY-NC 4.0).

(C) Copyright A.C. Jemilohunet al., 2017 Licensee PAGEPress, Italy

Gastroenterology Insights 2017; 8:7002 doi:10.4081/gi.2017.7002

depicted in Table 1. A review of a previously done computed tomographic (CT) scan showed four hypodense hepatic nodules of varying sizes (Figure 1). The nodules demonstrated peripheral enhancement with progressive centripetal filling till they were totally filled during the delayed phase. A repeat abdominal ultrasound scan confirmed the four hepatic masses. The lesions were of varying sizes, hyperechoic and fairly marginated (Figure 2). The largest lesion was in the left lobe measuring $73 \times 72 \mathrm{~mm}$ while the smallest was in the right lobe $(24 \times 20 \mathrm{~mm})$. All the masses demonstrated increased vascularity on color Doppler imaging. The intrahepatic ducts were normal. The abdominal CT scan and ultrasound features are consistent with hepatic hemangioma. A diagnosis of multiple hepatic hemangiomas was made. He was placed on Sorafenib $400 \mathrm{mg}$ BID. The patient took the drug erratically for a few weeks and later stopped because of financial constraint. He absconded from the clinic for several months, partly to seek alternative therapy. Twenty months after the initial diagnosis, the patient was well and alive, though still had infrequent mild abdominal pain. A repeat abdominal ultrasonography at this time showed no significant difference from the previous ones. 


\section{Discussion}

Hepatic hemangiomas are benign congenital mesenchymal tumors of the liver that are believed to grow silently over years from birth. ${ }^{1,3}$ The pathogenesis is not well known, but abnormal angiogenesis and vasculogenesis are suspects. ${ }^{3}$

The prevalence of hepatic hemangioma varies from one population to another. The reported incidence is about $2 \%$, but prevalence at autopsy ranges from $0.4-7.4 \%{ }^{1,7}$ It can occur at any age but mostly diagnosed in people between age 30-50 years., Hepatic hemangioma could be found in growing fetus and in infancy. 8,9 Women are usually more affected than men with a ratio of 4-6:1 as a result of the effect of the female sex hormones on the tumor. ${ }^{1,3,10}$ Women also present more than men at an earlier age and with larger tumors. ${ }^{1,3}$ There has been no definite familial or genetic mode of inheritance described, however, there was a report of a family from Italy in which 3 females in 3 successive generations had symptomatic hepatic hemangioma. ${ }^{11}$ Steroid therapy, ${ }^{12}$ estrogen and pregnancy can increase the size of an existing hemangioma. ${ }^{1,3}$

Most patients are asymptomatic, but symptoms that occur are nonspecific and common to other conditions. ${ }^{1,3}$ Symptoms are experienced by about $40 \%$ of patients with $4 \mathrm{~cm}$ hemangiomas and $90 \%$ of those with $10 \mathrm{~cm}$ tumors. ${ }^{13}$ Most symptoms are referable to rapid expansion, thrombosis or infarction leading to in inflammation, or stretching of Glisson's capsule. ${ }^{14}$ Pain in the right upper quadrant of the abdomen is the commonest complaint. ${ }^{1,3}$ Other symptoms include loss of appetite, early satiety, nau-

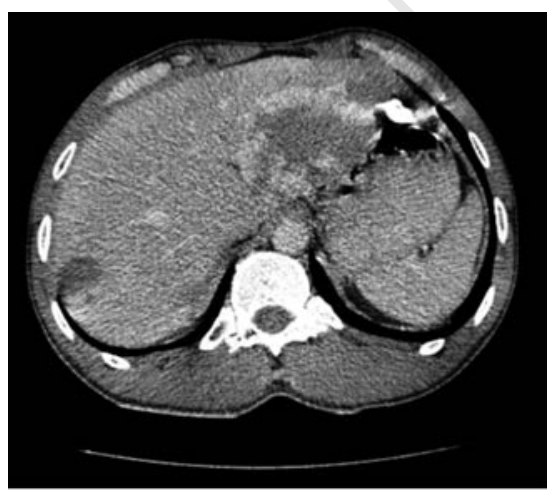

Figure 1. Portal venous phase of abdominal computed tomography scan demonstrating peripheral nodular enhancement of a left lobe lesion. Note another lesion on right lobe at segment VI. sea, vomiting. ${ }^{15}$ Physical examination may reveal an enlarged liver and an arterial bruit over the right upper quadrant. ${ }^{15}$ In regard to location, they are most often found in the right lobe of the liver. ${ }^{15}$ Atypical presentations include: heart failure from massive arteriovenous shunting, jaundice from bile duct compression, gastrointestinal hemorrhage from hemobilia and fever of unknown origin. $^{16}$

The case at hand had a right upper quadrant abdominal pain and abdominal ultrasound and CT scan findings consistent with multiple hepatic hemangiomas. The fact that one of the nodules was large enough to be classified as giant hemangioma $(>4 \mathrm{~cm})$ may be the reason for the

experience of pain by the patient since hepatic hemangiomas are often asymptomatic. The negativity of hepatitis $\mathrm{B}$ and $\mathrm{C}$ screening, alfa-fetoprotein, and other laboratory tests that are in keeping with a background chronic liver disease or hepatic malignancy supports the diagnosis of hepatic hemangioma in our patient. The benign nature of the liver disease is further corroborated by the relative stability of the patient 20 months after the initial diagnosis.

Hepatic hemangiomas can occur as part of some clinical syndromes like KlippelTrenaunay-Weber syndrome, KasabachMerritt syndrome, Osler-Rendu-Weber syndrome, Von Hippel-Lindau syndrome as well as in some cases of systemic lupus ery-

Table 1. Results of relevant laboratory tests in a Nigerian male with multiple hepatic hemangiomas.

\begin{tabular}{lc} 
Test & Results \\
Total bilirubin $(u p$ to 20 umol/L) & 25 \\
Conjugated bilirubin $($ up to 5 umol/L) & 10 \\
\hline Total protein $(58-80 \mathrm{~g} / \mathrm{L})$ & 76 \\
Albumin $(35-50 \mathrm{~g} / \mathrm{L})$ & 39 \\
\hline AST $(0-12 \mathrm{IU} / \mathrm{L})$ & 04 \\
ALT $(0-12$ IU/L) & 10 \\
\hline ALP $(0-35$ IU/L) & 16 \\
Platelet & $277,000 / \mathrm{cmm}$ \\
\hline HBsAg & Negative \\
Anti-HCV & Negative \\
\hline Alfa-fetoprotein & 5.09 ng/mL \\
Prothrombin time & Test-17s, Control-15s \\
\hline INR & 1.13 \\
PTTK & Test-37, Control-35s \\
\hline ESR & $11 \mathrm{~mm} / \mathrm{hr}$ (Westergren) \\
\hline
\end{tabular}

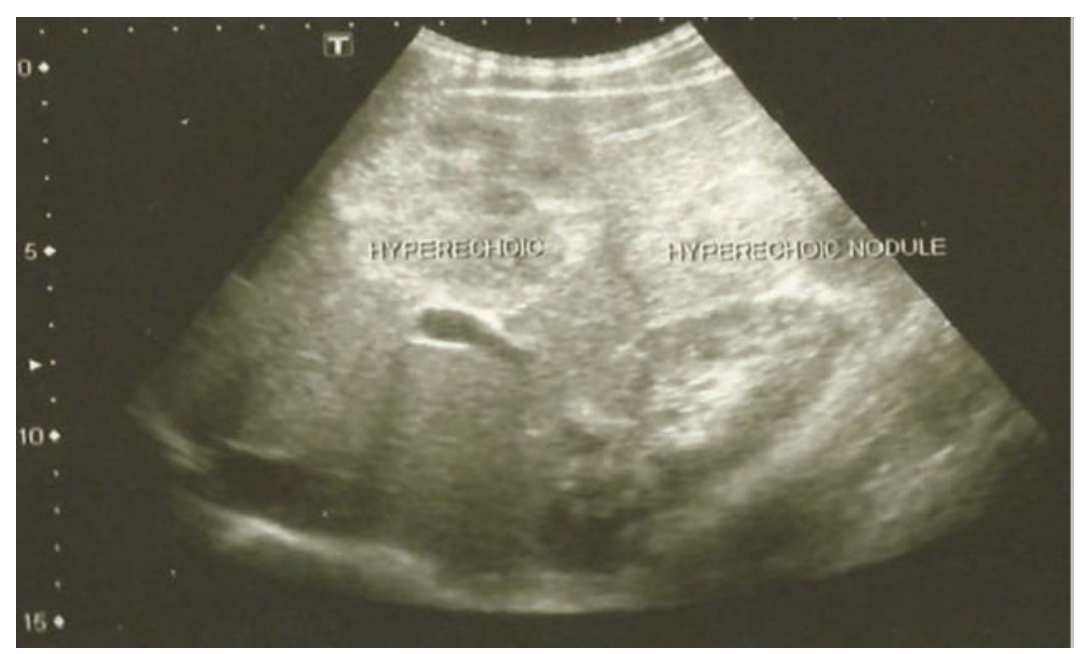

Figure 2. Abdominal ultrasound scan showing two hyperechoic nodules in the liver. 
thematosus. ${ }^{5,13}$ The commonly used initial diagnostic tool for hepatic hemangioma is ultrasonography which appears echogenic. ${ }^{1,15}$ Serial ultrasound examinations help to monitor increase in the size of the hemangiomas. Color Doppler ultrasound helps to increase the sensitivity and specificity of the test. ${ }^{1,15}$ Hepatic hemangiomas appear hypodense on dynamic contrast-enhanced CT scan. There may be enhancement of the peripheral portions of the lesion (ring or globular enhancement). ${ }^{1,15}$ Magnetic resonance imaging is highly sensitive and specific for diagnosis. ${ }^{1,15}$ Hemangiomas have a low signal intensity on T1 weighted images and high intensity on T2 weighted images. ${ }^{1}$ Routine laboratory studies are usually normal, just like we observed in our patient, but thrombocytopenia may be noted due to sequestration and platelet destruction. ${ }^{13}$

Although our patient had a fine needle aspiration of the liver at another facility before presenting to us, biopsy of hepatic hemangioma is contraindicated because of the high risk of hemorrhage. ${ }^{1}$

The medical management of hepatic hemangioma includes radiologic follow-up at 6 or 12 months after diagnosis. ${ }^{13}$ Bevacizumab, a monoclonal antibody which inhibits the activity of vascular endothelial growth factor, was reported to have caused tumor size reduction in a patient with hepatic hemangioma. ${ }^{17}$ Sorafenib, a multikinase inhibitor, was used to manage a patient with giant cavernous hemangioma in which the tumor volume reduced from $1492 \mathrm{~mL}$ to $665 \mathrm{~mL}$ after 78 days of treatment. ${ }^{18}$

Surgical therapy such as enucleation and resection may be indicated in symptomatic cases, spontaneous rupture, rapidly growing tumor and difficulty in differentiating hemangioma from hepatic malignancy. $1,15,19$

Other treatment modalities include transcatheter hepatic arterial embolization, radiofrequency ablation, and hepatic irradiation. Liver transplantation can be done as a last result for large or diffuse bilateral lesions. ${ }^{15}$

Although no randomized controlled clinical trial is currently available, the anecdotal report of tumor shrinkage in response to Sorafenib was not reproducible in this case. This may, however, be due to the inadequate medication adherence observed.

\section{Conclusions}

Though said to be a common liver pathology, reported cases of hepatic hemangioma are scarce in Nigeria. This particular patient is worth reporting because his condition constituted a diagnostic dilemma at the various health facilities where he presented before he was referred to our center. This brings to focus the need for physicians to always bear in mind that multiple hepatic masses are not always metastatic nodules or primary malignant lesions. A high index of suspicion for hepatic hemangioma could have reduced the number of diagnostic procedures he had. The multiplicity of the tumor and the giant size of one of them also make the case remarkable.

\section{References}

1. Ribeiro MAF, Papaiordanou F, Gonçalves JM, Chaib E. Spontaneous rupture of hepatic hemangiomas: A review of the literature. World J Hepatol 2010;2:428.

2. Adhikari DR, Thakur V, Telavane PP, et al. Hypergiant hepatic hemangiomas: case series. Indian J Surg 2015;77:40-2.

3. Toro A, Mahfouz AE, Ardiri A, et al. What is changing in indications and treatment of hepatic hemangiomas. A review. Ann Hepatol 2014;13:327-39.

4. Singh AP, Tanger R, Mathur V, et al. Unusual presentation of capillary he mangioma of liver in a neonate: a case report. J Evol Res Paediatr Neonatol 2016;2:13-5.

5. Di Carlo I, Koshy R, Al Mudares S, et al. Giant cavernous liver hemangiomas: is it the time to change the size categories? Hepatobiliary Pancreat Dis Int 2016;15:21-9.

6. Oluyemi AO, Adeyomoye AO, Awolola NA. Hepatic hemangioma and focal nodular hyperplasia in a Nigerian patient with hepatitis B virus infection. Int J Case Reports Images 2012;3:8-10.

7. Schwartz SI, Husser WC. Cavernous hemangioma of the liver. A single insti- tution report of 16 resections. Ann Surg 1987;205:456-65.

8. Gembruch U, Baschat AA, GloecknerHoffmann K, et al. Prenatal diagnosis and management of fetuses with liver hemangiomata. Ultrasound Obstet Gynecol 2002;19:454-60.

9. Huang SA, Tu HM, Harney JW, et al. Severe hypothyroidism caused by type 3 Iodothyronine Deiodinase in Infantile Hemangiomas. N Engl J Med 2000; 343:185-9.

10. Giannitrapani L, Soresi M, La Spada E, et al. Sex hormones and risk of liver tumor. Ann NY Acad Sci 2006; 1089:228-36.

11. Díez Redondo P, Velicia Llames R, Caro-Patón A. [Familial hepatic hemangiomas]. Gastroenterol Hepatol 2004;27:314-6. [Article in Spanish]

12. Takahashi T, Kuwao S, Katagiri H, Kakita A. Multiple liver hemangiomas enlargement during long-term steroid therapy for myasthenia gravis. Dig Dis Sci 1998;43:1553-61.

13. Goodman Z. Benign tumors of the liver. In: Okuda K, Ishak KG, eds. Neoplasms of the liver. Tokyo: Springer-Verlag; 1987. pp 105-25.

14. Chamberlain RS, Oelhafen K. Benign hepatic neoplasms. In: Abdeldayem H, ed. Hepatic Surgery. InTech; 2013. pp 279-9.

15. Bajenaru N, Balaban V, Săvulescu F, et al. Hepatic hemangioma; review. J Med Life 2015;4-11.

16. Mikami T, Hirata K, Oikawa I, et al. Hemobilia caused by a giant benign hemangioma of the liver: report of a case. Surg Today 1998;28:948-52.

17. Mahajan D, Miller C, Hirose K, et al. Incidental reduction in the size of liver hemangioma following use of VEGF inhibitor bevacizumab. J Hepatol 2008; 49:867-70.

18. Yamashita S, Okita K, Harada K, et al. Giant cavernous hepatic hemangioma shrunk by use of sorafenib. Clin J Gastroenterol 2013;6:55-62.

19. Belli G, D'Agostino A, Fantini C, et al. Surgical treatment of giant liver hemangiomas by enucleation using an ultrasonically activated device (USAD). Hepatogastroenterology 2009;56:2369. 